\title{
A AUTO-IMAGEM CORPORAL NA ANOREXIA NERVOSA: UMA ABORDAGEM SOCIOLÓGICA ${ }^{1}$
}

\author{
Rubia Carla Formighieri Giordani \\ Universidade Federal do Paraná
}

\begin{abstract}
RESUMO: A anorexia é um transtorno no comportamento alimentar com a distorção na auto-imagem corporal, sendo sua principal característica o medo mórbido de engordar e uma forma pervertida de realizar a restrição alimentar. O objetivo deste trabalho foi compreender os mecanismos de formação da imagem corporal na anorexia nervosa, bem como depreender os sentidos manifestos na construção da obesidade no corpo anoréxico. O caminho metodológico trilhado compreendeu a etnografia e o método biográfico, com a coleta de histórias de vida de anoréxicos. É um trabalho descritivo e interpretativo sobre a questão da imagem corporal na anorexia nervosa e, para tanto, dialoga com a Sociologia e com a Psicologia. Diante da análise do conteúdo dos depoimentos, nota-se que a construção da imagem corporal não é um trabalho solitário, mas resulta da intercomunicação entre o indivíduo e o mundo social. $\mathrm{O}$ indivíduo utiliza outras imagens para definir sua própria imagem corporal, bem como esse processo implica numa troca relacional entre indivíduos.
\end{abstract}

PALAVRAS-CHAVE: anorexia nervosa; imagem corporal; corpo.

\section{BODY IMAGE IN NERVOUS ANOREXIA: A SOCIOLOGICAL APPROACH}

\begin{abstract}
Nervous anorexia is an eating disorder that involves body image distortion and includes, among other characteristics, morbid fear of putting on weight and a distorted form of performing dietary restrictions. The aim of the present work was to understand the mechanisms underlying body image formation in nervous anorexia as well as to infer meanings manifested in the construction of obesity in the anorexic body. The methodology adopted comprised the ethnographical approach and the biographical method, including a collection of life stories of anorexic subjects. It is a descriptive and interpretive work about body image in nervous anorexia, thus interacting both with Sociology and Psychology. After analyzing the contents of the statements one realizes that body image construction is not a one-person job, but rather the result of the interaction between the individual and his/her social world. The individual makes use of other images in order to define his/her own body image, a process that also implies a relational exchange between individuals.
\end{abstract}

KEYWORDS: nervous anorexia; body image; body.

\section{Psicopatologia}

A Anorexia Nervosa é um tipo de Transtorno Alimentar que envolve "severas perturbações no comportamento alimentar" do indivíduo, sendo sua principal característica o medo mórbido de engordar (APA, 1994, pp.511-513). A sua incidência têm aumentado nas últimas décadas, especialmente entre as mulheres jovens dos países ocidentais (Dunker \& Philippi, 2003, p.52; Hay, 2002, p.16). Dados epidemiológicos têm mostrado que a incidência média anual da anorexia nervosa na população em geral é de 18,5 por 100.000 entre as mulheres e 2,25 por 100.000 entre os homens (Hay, 2002, p.14).

Os relatos iniciais de um padecimento auto-imposto através da restrição alimentar datam da Idade Média e na época estavam relacionados a uma conduta religiosa de privação (Bidaud, 1998; Herscovici \& Bay, 1997).

O médico William Gull foi quem atribuiu ao transtorno o termo anorexia nervosa, relacionando sua maior incidência entre as mulheres jovens e identificando, mais precisamente, alguns sinais físicos da doença (Herscovici \& Bay, 1987; Robell, 1997; Turner, 1984). Na verdade, o termo anorexia nervosa seria inadequado, pois do grego an significa ausência e orexis apetite; todavia, não se trata absolutamente de uma ausência de apetite, mas da recusa consciente e obstinada do indivíduo em alimentar-se com o intuito de perder peso.

Em 1873, o psiquiatra francês Lasègue publica na França De l'anorexie hystérique e insiste na causa psiquiátrica da doença (Bidaud, 1998; Herscovici \& Bay, 1987). Lasègue é o responsável pelo avanço no conhecimento acerca das distorções que a anoréxica tem de seu corpo, bem como sobre a negação da gravidade de seu estado. Lasègue observou que a doença era caracterizada por uma forma pervertida de realizar a restrição alimentar e atribuiu ao transtorno o nome de anorexia histérica. Lasègue observa que há uma condescendência verdadeiramente patológica da anoréxica com relação ao seu estado cadavérico, pois a anoréxica não deseja a cura, como também se regozija nas restrições que sua conduta lhe impõe (Bidaud, 1998).

Talvez Charcot, na publicação Disorders of the nervous system, datada de 1889 , em Londres, é que tenha re- 
conhecido a característica psicopatológica central da anorexia: a idéia fixa da obesidade (Bidaud, 1998; Cordás \& Claudino, 2002; Turner, 1984). Posteriormente, na França, em 1895, Freud \& Breuer, nos trabalhos sobre a histeria, contribuem também ao estudo da anorexia, relacionado-a a uma síndrome histérica (Turner, 1984).

Os conceitos psicanalíticos influenciam até hoje na explicação da doença, mas são os estudos de Hilde Bruch que conferiram avanços do ponto de vista da psicopatologia da anorexia nervosa. Bruch destaca que a anoréxica faz uma distorção de sua imagem corporal, aliada a uma dificuldade em interpretar os sinais de necessidade do corpo e uma sensação de ineficácia (Cordás \& Claudino, 2002; Herscovici \& Bay, 1987). Para Hilde Bruch, "a recusa franca de se reconhecer doente e a ausência de angústia diante de um emagrecimento freqüentemente macabro dão o último retoque ao perfil clínico" (Bruch, citado em Bidaud, 1998, p.24).

O Manual Diagnóstico e Estatístico de Transtornos Mentais, em sua quarta edição, (DSM-IV - APA, 1994), que contém desde as primeiras definições de Lasègue e Gull até as discussões mais recentes, apresenta as características diagnósticas da Anorexia Nervosa, como: “(...) a recusa do indivíduo a manter um peso corporal na faixa normal mínima, um temor intenso de ganhar peso e uma perturbação significativa na percepção da forma ou tamanho do corpo. Além disso, as mulheres pós-menarca com este transtorno são amenorréicas (...)" (p. 510). As anoréxicas experimentam a dismorfia corporal, uma excessiva inquietação com algum aspecto de sua aparência, que pode ser irreal ou real (no caso de ser real, é desproporcional), e que gera grande sofrimento.

Algumas vezes esses indivíduos podem se dedicar a realização de exercícios intensos para queimar calorias e perder peso, e adotar métodos purgativos como a autoindução do vômito e abuso de laxantes ou diuréticos.

O DSM-IV (APA, 1994) descreve dois subtipos de anorexia nervosa para distinguir a presença ou ausência de compulsões periódicas ou purgações regulares durante o episódio atual de anorexia. $\mathrm{O}$ tipo restritivo é quando o emagrecimento ocorre em virtude de dietas, jejuns ou exercícios em excesso. O tipo compulsão periódica purgativa ou bulímica ocorre quando o indivíduo dedica-se regularmente a purgações que incluem vômitos auto-induzidos, abuso de laxantes ou diuréticos durante o episódio atual de anorexia nervosa.

O pensamento constante do medo de engordar não é aliviado pelo emagrecimento, mas, ao contrário, freqüentemente, na medida em que o sujeito diminui o peso, aumenta o seu medo de engordar. Esses indivíduos apresentam uma distorção da sua imagem corporal de tal forma que, mesmo extremamente magros, podem avaliar-se "gordos", ou ainda, sentirem-se magros, mas permanecendo preocupados com partes "gordas" de seu corpo. O peso corporal é altamente valorizado, sendo a perda de peso apreciada e julgada como uma extraordinária conquista e uma formidável demonstração de auto-controle.

Este estudo teve como objetivo compreender os mecanismos de formação da imagem corporal na anorexia nervosa, bem como depreender os sentidos manifestos na construção da obesidade no corpo anoréxico. É um trabalho descritivo e interpretativo sobre a questão da imagem corporal na anorexia nervosa e, para tanto, dialoga com a Sociologia e com a Psicologia. Discute-se como se dá a construção da obesidade no corpo anoréxico e das imagens que a anoréxica constrói acerca do seu corpo.

\section{Método}

Este trabalho consiste numa abordagem sociológica sobre a questão da imagem corporal na anorexia nervosa, a compreensão de sentidos que o anoréxico constrói para a obesidade e a imagem da obesidade no corpo anoréxico. É uma reflexão que repousa sobre a relação entre a subjetividade e o corpo, e, nesse sentido, a metodologia qualitativa de pesquisa em ciências socais revelou-se fecunda para descrever o vivido pelo sujeito anoréxico, sua subjetividade e suas construções sobre aquilo que ele experimentou corporalmente. Assim, a etnografia e o método biográfico foram utilizados complementarmente para a compreensão da construção da imagem corporal na anorexia nervosa.

A perspectiva de descrever a experiência da doença em primeira pessoa envolve a elaboração de uma narrativa por parte do sujeito, e que pressupõe uma espécie de reflexão sobre o que aconteceu, uma volta ao passado sempre apreendido, marcado, tonificado pelo que lhe é atual (Schutz, 1979). Ao interpretar fatos passados, o indivíduo lança mão de seu estoque de conhecimento "um código de interpretações de suas experiências passadas e presentes, e também determina sua antecipação das coisas que virão", é o resultado de experiências anteriores apreendidas e transformadas em posse habitual para o indivíduo (Schutz, p.74).

Para Ferraroti (1988, citado em Bueno, 2002), a especificidade do método biográfico reside justamente no seu caráter de intensa historicidade e singularidade. A relação entre a história do indivíduo e a sociedade da qual faz parte se expressa nas totalizações da sociedade global através do microcosmo social onde vive o indivíduo: a família, escolares, a vizinhança; num sentido lato, a biografia do indivíduo é uma micro-relação social.

A biografia é subjetiva em muitos aspectos, pois é um relato autobiográfico através de um documento escrito, que deriva de "um sujeito-objeto" que se observa e se reencontra; ou um documento oral, onde emergem as interações observador - observado (Ferraroti, 1988, citado em Bueno, 2002). Cabe, então, considerar a subjetividade não como um viés ou inferência, mas como 
um dado que a priori deve compor a contextualização das narrativas. Nesse sentido, também é que a dimensão do pesquisador e suas impressões e interpretações resultantes da interação social em que está imerso durante a pesquisa são dados etnográficos relevantes à pesquisa, pois "toda entrevista é uma interação social completa, um sistema de papéis, expectativas, de injunções, de normas e valores implícitos, e por vezes até de sanções" (Ferraroti, 1988, citado em Bueno, 2002).

Nessa perspectiva, o material empírico utilizado comportou: 1) a narrativa autobiográfica realizada em situação face a face com indivíduos que tiveram diagnóstico de anorexia nervosa, já recuperados ou em tratamento. A técnica utilizada foi da história de vida oral sem roteiro estruturado. Utilizou-se ainda toda sorte de dados etnográficos: depoimentos dos pais, cartas, diários, dados clínicos e fotografias, com o objetivo de enriquecer as histórias contadas.

O trabalho de campo foi realizado na cidade de Curitiba no período de janeiro a setembro de 2003. Os locais para os encontros eram sempre escolhidos pelo informante, dado o teor e a confidencialidade dos depoimentos. Os nomes dos informantes também foram trocados por nomes fictícios para preservar as identidades.

No total, foram estudadas oito histórias de vida de indivíduos do sexo feminino, pois durante o período de realização do trabalho de campo não havia pacientes do sexo masculino para serem encaminhados para participarem do estudo. As faixas etárias variaram sensivelmente (duas adolescentes de 16 anos, cinco jovens de idade entre 18 e 23 anos e uma mulher casada de 26 anos). A renda familiar também variou, desde um salário mínimo até trinta e três salários mínimos, e com níveis diferentes de escolaridade.

Outro ponto importante relativo às entrevistadas refere-se aos diferentes níveis no tratamento em que elas se encontravam e história clínica pregressa: a maioria já havia se recuperado da anorexia, permanecendo em acompanhamento psiquiátrico (apenas uma informante desenvolveu um tipo de compulsão alimentar e que direcionou bastante o seu depoimento); teve um caso de uma jovem que havia tido uma recaída (era o seu segundo episódio anoréxico) e duas entrevistadas estavam passando por um episódio (sendo uma delas internada para o tratamento).

\section{Resultados e Discussão}

\section{A Imagem Corporal na Anorexia Nervosa: para além do Corpo}

Do que é feito ou o que propriamente demarca os limites do corpo? Trata-se ele tão somente de um espaço físico e limite da individualidade ou suas fronteiras vão além, se alargando, sobretudo, ao espaço social em que é cultivado, incorporando dados do mundo e sendo marcado por ele, ao passo que esse encontro inscreve sentido sobre a espaço/temporalidade em que ele mesmo se fundamenta? Para Merleau Ponty (2000):

o corpo é feito da mesma carne que o mundo (é um percebido) e que para mais essa carne de meu corpo é participada pelo mundo, ele a reflete, ambos se imbricam mutuamente, (o sentido a um tempo auge de subjetividade e auge de materialidade), encontramse na relação de transgressão e encadeamento (p.225).

É um sujeito e um objeto, um corpo que sente e ao mesmo tempo é sentido. Não é somente um objeto no mundo, mas é um corpo sensível e perceptível.

Para as anoréxicas, os limites do corpo quase se apagam diante das circunstâncias em que vivem, do cotidiano de seus relacionamentos, dessa rede de relações concretas e afetivas em que estão submersas. Toda condição e situação que a rigor está matizada nessa imagem disforme que a anoréxica tem de si mesma e que se expressa pela insatisfação com o tamanho do seu corpo e a perda de peso.

A negação da gravidade do seu estado físico é sinal da presença da anorexia e se manifesta na incompreensão dos limites do seu corpo e nessa forma perturbada de vivenciar o baixo peso. Clinicamente, o indivíduo com anorexia põe em xeque a própria vida; o aspecto cadavérico, a pele ressecada e pálida, a queda de cabelo podem não provocar qualquer mudança no itinerário auto-imposto de abstinência e purgação. $\mathrm{O}$ seu projeto continua sendo emagrecer, livrar-se da gordura. Numa espécie de lucidez amarga que é destilada através do discurso sobre a doença, o sujeito conhece os riscos, mas os desconsidera completamente.

O corpo que se mostra é um corpo descorado e fraco; mas para o anoréxico que se vê, a magreza nunca é suficiente e o excesso é latente à sua condição. De acordo com Merleau Ponty (1999), o corpo-sujeito e o corpo-objeto estão justapostos através de uma mesma relação de possibilidade, e esse corpo-sujeito, ao mesmo tempo em que sente, pode também ser sentido. É no cruzamento de possibilidades entre corpo-sujeito e corpo-objeto que essa doença cria um paradoxo entre o corpo real e a imagem do corpo que o indivíduo anoréxico projeta para si na anorexia, a percepção auto-referida de imagem corporal é transbordante e está além dos limites do pequeno corpo anoréxico.

Para compreender melhor esse ponto, utilizou-se o conceito de imagem corporal de Schilder (1999), que extrapola os aspectos neurológicos, mas relaciona-se às conexões entre o indivíduo e o mundo ao seu redor. Para o autor, a imagem corporal está além dos limites do corpo físico, as noções de espaço interno e externo na imagem corporal não são as mesmas da física. Segundo Schilder (1999): 
Entende-se por imagem do corpo humano a figuração de nosso corpo formada em nossa mente, ou seja, o modo pelo qual o corpo se apresenta para nós. Há sensações que nos são dadas. Vemos partes da superfície do corpo. Temos impressões táteis, térmicas e de dor (...) Além disso, existe a experiência imediata de uma unidade corporal. Esta unidade é percebida, porém é mais do que uma percepção. Nós a chamamos de esquema de nosso corpo (...) de modelo postural do corpo. O esquema do corpo é a imagem tridimensional que todos têm de si mesmos. Podemos chamá-la de imagem corporal (p.7).

A imagem do corpo não advém somente de impressões ou sensações táteis, mas relaciona-se à figurações e representações sobre o corpo. À figuração do corpo estão amarradas imagens que se sustentam sempre numa relação com alguma coisa. Através da imagem, o sujeito armazena uma relação, uma situação, ou seja, a imagem do objeto relaciona-se à forma como este foi percebido. Tavares (2003) lembra oportunamente como "a imagem mental da aparência de uma refeição poderá fazê-la mais ou menos saborosa" (p.33). É exatamente isso que se percebe na anorexia nervosa, o caso de uma imagem corporal auto-apreendida que atravessa o próprio corpo e que está das fronteiras físicas do corpo.

$\mathrm{Na}$ anorexia nervosa, a representação mental que o sujeito opera sobre o seu corpo é incoerente à sua realidade carnal; a anoréxica representa o seu corpo sempre gordo. Essa auto-imagem deslocada da realidade da carne, em excesso e extravagância, é a máxima instigante dessa patologia, insatisfação propulsora e contínua que irá apagar, através da abstinência resoluta e sem fim, os limites plásticos do seu corpo. Nessa clivagem, entre aparência e realidade, entre o distanciamento da imagem real do corpo e a auto-imagem percebida, crescem a insatisfação e a tentação de prosseguir. A anorexia tensiona uma espécie de lipofobia e seu par indissociável, o prazer na magreza. Nesse sentido, observa-se o depoimento de Kely sobre o período em que esteve doente:

Não lembro se foi um período que eu me sentia muito mal. Me sentia bem em estar magra! Excessivamente magra! Tanto que eu usava calça trinta e quatro, calça infantil e ainda sobrava... Era legal... E eu tinha umas coisas de deitar na cama e medir, o buraco da perna... o buraco da perna não podia aumentar. Não me sentia doente, até na verdade, mais no final, quando eu tava emagrecendo bastante, eu até achava meio perigoso assim de repente, né! ... Eu sentia... às vezes me sentia feia, me sentia gorda! (aumenta a voz) Chegava a me sentir gorda mesmo estando magra... mas por falta de estar emagrecendo! ... Mas aí eu me sentia gorda, chegava a me sentir gorda várias vezes, daí eu me sentia mal assim... 'Tô me sentindo gorda, mas eu já emagreço!' - 'Minha barriga tá grande!'; nunca tive barriga, imagine se naquela época minha barriga ia estar grande! Daí eu via pelanca aqui (mostra os dedos), via pelanca na mão, era uma coisa absurda assim, tudo tinha gordura... E nada era o suficiente... Mas eu me olhava muito no espelho, muito, todo dia, toda hora, né; então tinha aquela obsessão: qualquer coisa que parecesse fora do lugar, eu já me sentia gorda, né, falava: - "Ai, que que é isso?", tipo "Uma gordurinha, vou emagrecer mais!", entendeu, "Vô emagrecer pra tirar isso aqui!" Tinha o prazer físico de se tocar, entendeu? De sentir as costelinhas aparecendo, de ver os buracos do corpo aparecendo, afundando mais, então essa era uma sensação corporal que... que era agradável sim. Por mim eu emagreceria em uma semana, emagreceria cinco quilos na outra semana, mais cinco na outra, mais cinco na outra, mais cinco... até zerar, entendeu, virar uma formiguinha! (Kely, 23 anos)

A gordura é um tipo de interferência na simetria corporal, na organização e na limpeza das formas; na obsessão pela linha reta, cada extensão do corpo conjuga cálculo exato e polimento na figura do corpo. Kely vestia-se com seu corpo, e, ao torná-lo como que um objeto para seu deleite, faz dele um simulacro onde se mantêm aprisionada sob a ilusão de libertar-se das rotinas fisiológicas. Insatisfeita com pouco mais de trinta e cinco quilos e determinada a "virar uma formiguinha", impressionava à todos com tanta disposição em suas atividades diárias. Quando fala que às vezes sentia-se gorda, chega a mudar o tom da voz durante a entrevista, mostrando-se irritada com a possibilidade de estar gorda.

Dinora que tem uma história de sobrepeso anterior à anorexia, conta que sentia-se socialmente discriminada pelo excesso de peso. Seu depoimento é marcadamente entoado por grande sofrimento subjetivo, e, várias vezes, atribui como causa de sua doença o fato do sobrepeso ter se constituído uma marca social, um tipo de atributo depreciativo imputado à sua pessoa (Goffman, 1988).

Quando eu passei do meu peso, eles começaram a me chamar de gorda... então eu tentei abaixar o meu peso e fui deixando de comer... Sempre me lembrava do tempo que me chamavam de gorda, isso não saía da minha cabeça... Isso me levou a... Quando as pessoas me chamavam de gorda eu pensava que tinha que fazer regime... todo mundo tirava sarro... parecia que todo mundo olhava pra mim e me achava gorda (chora e faz um grande silêncio) (Dinora, 26 anos).

É exatamente o valor que o atributo físico adquire na vida social do indivíduo que pode estigmatizá-lo. É a linguagem que ecoa nas relações cotidianas que desempenha o norte orientador para a constituição de uma imagem corporal no sujeito. Dinora, em algum momento, assumiu como sua imagem real, essa imagem disforme e desvalorizada de indivíduo, e simbolicamente parece 
ser exatamente dessa "gordura" que ela tenta se livrar.

A imagem corporal não é um conceito abstrato, nem a imagem obesa percebida pela anoréxica, um delírio, tipo de distorção no seu pensamento. A imagem corporal num contexto existencial é a revelação de uma identidade, de um sujeito na história de suas relações concretas. Para um corpo que possui história e memória, toda essa rede de informações que singulariza o indivíduo vai formar uma identidade corporal (Tavares, 2003).

A formação de uma identidade corporal nasce da intercomunicação e das trocas sociais entre os indivíduos. $\mathrm{O}$ "eu" é uma "estrutura social que se desenvolve inteiramente numa experiência de comunicação" (Joseph, 2000, p. 21). É um self que individualiza na divisão do eu com o mundo. É o resultado da vida social fora de si mesmo (Joseph, 2000), e, utilizando a expressão de Merleau Ponty (2000), é o ser-no-mundo através do corpo e do que ele representa ou carrega. Essa forma como o indivíduo representa a sua identidade corporal constitui sua imagem corporal (Juviniano, 2003).

Na construção de uma auto-imagem corporal, onde o objeto em foco é o próprio sujeito, outras referências exteriores também são apropriadas pelo indivíduo para serem incorporadas, poderia-se até dizer que outras imagens próximas e significativas são usadas. Por exemplo, para Ana Maria, a imagem corporal da mãe e a preparação da refeição estão imbricadas à percepção do seu próprio corpo:

Via que a doença estava acontecendo porque eu estava deixando, mas ao mesmo tempo eu não conseguia parar com aquilo. Ela (a mãe) estando em casa eu acabava ficando nervosa com ela porque ela fazia um monte de comida e também ela fez uma cirurgia do estômago, aquela para reduzir o estômago. Ela emagreceu um monte também... uns vinte quilos e até isso eu comecei a me comparar com ela, porque "se a minha mãe não consegue comer, por-que eu preciso comer?" (Ana Maria, 19 anos).

De acordo com Schilder (1999), "nossa imagem corporal só adquire suas possibilidades e existência porque nosso corpo não é isolado" (p.311) e a estruturação da imagem corporal se dá no contato e na troca contínua com outras imagens corporais. Ainda para o autor:

não utilizamos uma mera figura teórica ao dizer que a dor e o sofrimento de um indivíduo nunca podem ser vistos como um fenômeno isolado. As leis de identificação e comunicação de imagens corporais transformam o sofrimento e a dor do indivíduo numa preocupação de todos (p.310).

Ana Maria tinha dificuldade para comer ao lado da mãe e de sua imagem espremida entre a vontade de comer e a impossibilidade devido a cirurgia.

Existe ainda um corpo imaginário, esboçado e idealizado pelos outros para o sujeito, e ele tem de lidar tam- bém com essas expectativas. No contato do indivíduo com esse corpo imaginário e cultural emerge a identidade corporal; em total singularidade "o ser humano se relaciona tanto à sua estrutura orgânica ímpar como ao espaço único que lhe é dado ocupar no mundo de relações" (Tavares, 2003, p.83). Para Berger e Luckman (1999), a identidade é produzida na relação dialética entre um indivíduo e a sociedade, disso decorre que muitas vezes a identidade corporal, fruto dessa relação, pode conter elementos marcados no seu corpo que o indivíduo não consegue ainda identificar; ele vivencia uma imagem e não consegue explicar. Sueli, por vezes, fala da insistência em emagrecer como a realização de um desejo misterioso:

É algo inconsciente... Minhas amigas e até minha família não entendem minha situação e às vezes ficam bravas e se revoltam, mesmo eu explicando não consigo lutar contra isso. Eu quero me curar e pôr um freio nisso, mas nunca vou conseguir explicar o que realmente aconteceu. Parece uma coisa que colocaram na minha cabeça ou algo que aconteceu comigo e eu não sei (Sueli, 16 anos).

Sueli, num outro momento, reclama sobre sentirse pressionada socialmente para cumprir exigências com relação ao seu corpo. Acha que a imagem sem dúvida é um princípio de inclusão ou de exclusão. Para ser bem aceita nos relacionamentos, é fundamental cuidar tão bem do corpo quanto se cuida da alma:

- Eu li numa revista sobre anorexia e fiquei com vontade de ter para ser muito magra... li aquela reportagem e acho que inconscientemente eu desenvolvi a anorexia. Eu lia muito Boa Forma, e, se você for ver no armário quanta Boa Forma tem aí... E isso é muito ruim sabe? As revistas fazem muito mal... Eu acho que comecei a me sentir mais feia depois que comecei a ler...

- Mas você não é feia... (respondo)

- Ahhhh... mas vai ver uma Daniela Cicarelli, sei lá, uma dessas modelos aí, todo mundo baba e você vai se sentir pior. Na verdade se você tem cinqüenta e oito quilos pensa "nossa sou uma baleia!" Nossa eu acho revista uma coisa ridícula, parece que fazem pensando para deixar a pessoa mal! E eu acho que a imagem que você passa para os outros importa muito! (Sueli)

Os modelos tipificados sobre atratividade e feminilidade do corpo feminino, que tão comumente têm estado indissociável da magreza nas sociedades contemporâneas ocidentais (Baudrillard, 1995), podem aparecer transfigurados nos discursos individuais. Os valores culturais que têm impingido sobre os corpos tantas práticas e cuidados e que podem compor a gênese de tanto desacordo e insatisfação entre o corpo real e a imagem idealizada pela anoréxica, por vezes, estão metamorfoseados nos relacionamentos sociais do indivíduo, outras vezes 
são paradoxalmente ignorados.

- Você tinha algum modelo de beleza? (pergunto)

- Não, não, não!!! Eu nunca olhei revista! (responde sonoramente)

- Você tinha medo de comer? (pergunto)

- Porque? Eu já falei antes... porque me chamavam de gorda! (Dinora, 27 anos)

(...) acho que não foi por uma questão estética... por mais que as pessoas achem isso! Acho que foi mais uma coisa assim de auto-afirmação, de auto-confiança... Era um momento que eu já tinha feito várias coisas pra minha idade e queria uma definição de vida. Eu não me encontrava, então tudo que eu fazia não me sentia completa. Acho que foi uma forma, eu imagino, que eu encontrei pra de repente me sentir capaz de fazer alguma coisa que eu me propunha; tipo uma meta a ser atingida. E deu certo porque me propunha: 'Ah! Hoje vou emagrecer meio quilo... até o final do mês emagreço mais cinco!' Foi indo, fui fazendo e deu certo! Ầ princípio nunca fui gorda! (Kely, 23 anos)

Dinora confessa que nunca se interessou por assunto de moda ou corpo e sequer lia revistas do gênero, fala que nunca teve por objetivo emagrecer para tornar-se mais atraente, mas que precisava apenas livrar-se dos tormentos diários a que era submetida. Já Kely parece mais uma adepta confessa de um tipo de beleza funcional para usar uma expressão de Baudrillard (1995): um corpo "retomado na sua materialidade como objeto de culto narcisista ou como elemento de tática e de ritual social" (p.139). Enfrentando dificuldades para lidar com os conflitos internos, passa a investir no corpo, ou, melhor dizendo, na sua auto-imagem corporal.

Sueli, que iniciou a anorexia quando tinha apenas doze anos, também fala que a perda de peso simbolizou uma mudança em sua vida, como que uma transformação em sua identidade pessoal. Para Goffman (1988), a identidade pessoal envolve a noção de unicidade, de uma "marca positiva ou apoio de identidade" (p.66). Relaciona-se ainda a "fatos biográficos" que vão se agregando aos aspectos diferenciais desse indivíduo com relação aos outros. A mudança na identidade pessoal que sugere Sueli é uma espécie de projeto identitário, e que consiste na realização de uma identidade ideal. Isso depende, por assim dizer, do nível de aproximação entre a percepção auto-referida de imagem corporal e o padrão corporal que o sujeito coloca para si. Diante de uma proposta inacessível e de um nível de insatisfação crescente, nasce uma angustiante jornada de auto-aperfeiçoamento.

Eu sempre fui gordinha e tiravam muito sarro de mim, daí enchi o saco e pensei: "Vou fazer uma dieta para emagrecer... vou chegar no colégio magrinha, diferente, pra ver se muda alguma coisa!" Daí fiz dieta e em quinze dias perdi um monte de peso, também cresci e fiquei mais esbelta. Daí, depois comecei a ficar com neurose, vi que não tava magra o suficiente e que tinha que emagrecer mais e mais... daí eu pirei! ... Eu falava que tinha que ser magrinha, nem que fosse um esqueleto... Eu não queria ser magra, queria ser seca entendeu? Não queria ter um pingo de gordura pra ninguém botar um defeito em mim, queria ser perfeita!... Porque a pessoa vendo que as pessoas estão gostando da imagem que ela está passando, ela vai ter uma auto-estima melhor. Eu ainda ligo bastante pra minha imagem, só que agora estou mais auto-confiante! (Sueli, 16 anos)

A imagem corporal nunca permanece fixa ou uniforme, mas deriva de um esforço permanente do sujeito para transpor essa identidade corporal. E isso se evidencia no movimento à abertura e reestruturação coerente à alteração das situações concretas em que o indivíduo se encontra. Para Tavares (2003), "a imagem corporal não se baseia apenas em associações, memórias e experiências, mas também em intenções, aspirações e tendências" (p.76).

Sueli deleitava-se em sua condição anoréxica: ao se reapropriar de seu corpo, descobre nele a possibilidade de realizar-se, e, ao ritualizá-lo, sustenta sua realidade subjetiva. O trato com o seu corpo é a expressão pura dessa busca de uma nova identidade, e essa estranha sensação de segurança proporcionada pela negação da comida é que alimentava a sua fome insaciável para emagrecer.

Diante dessa imagem distorcida, cabe uma questão importante, a saber, como se dá a construção da obesidade no corpo anoréxico? Françoise Dolto desenvolveu o conceito de imagem corporal para falar de uma dimensão corporal - não a realidade carnal do contato com o mundo físico, que para a autora seria o esquema corporal - mas de uma dimensão que é animada pela comunicação relacional com os outros, as trocas linguageiras de sujeito para sujeito (Dolto, 2001).

É certo que esse esquema corporal, do qual fala Dolto, é o meio para o sujeito objetivar sua imagem corporal, entretanto, a estruturação da imagem corporal se dá pela historicidade de cada sujeito, nas suas relações com os outros:

é a síntese viva de nossas experiências emocionais (...) é, a cada momento, memória inconsciente de todo o vivido relacional, ao mesmo tempo, ela é atual, viva, em situação dinâmica, simultaneamente narcísica e inter-relacional: camuflável ou atualizável na rela-ção aqui e agora (Dolto, 2001, pp.14-15).

É esse vivido relacional que se projeta a cada momento quando a anoréxica relembra através dessa imagem corporal seu passado - lugares e relacionamentos, sonhos e fracassos -, um tipo de inscrição permanentemente presente por meio do corpo.

A formação da imagem corporal do indivíduo per- 
passa pela intersubjetividade, pelas trocas linguageiras e no reconhecimento pelo seu interlocutor enquanto sujeito. É, portanto, a partir "da comunicação entre sujeitos e o vestígio do dia-a-dia, memorizado" (Dolto, 2001, p.15) que surge a imagem corporal num retrocruzamento, onde o passado ecoa na relação presente. Sobre isso Kely, teoriza em seu depoimento:

É por isso que a gente sofre... eu acho que eu tenho tantas conseqüências... por mais que eu não sofra dramaticamente com isso hoje, eu tenho conseqüências daquilo que eu provei no meu corpo, porque ele também... eu acho, ele é o meio mais forte de ex-pressão daquilo que eu penso e daquilo que eu faço. Então, a partir do momento que eu privo meu corpo... eu acho que ele sofreu com isso por muito tempo. Até hoje ele está despejando na minha vida questões a serem resolvidas (Kely, 23 anos).

Para Kely, o corpo não é apenas simulacro ou reservatório de intervenções, não é mero instrumento a serviço de operações mentais, mas é síntese viva que convoca sentido e provoca o sujeito. Seu corpo é sua marca no mundo, expressão sua no mundo.

Esse conhecimento radicado no corpo é a marca viva de um passado relacional, apreendido e transformado em conhecimento tipificado, uma espécie de maneira prática de engajar-se e responder às solicitações que o mundo social faz ao indivíduo. Tudo isso forma uma imagem corporal cristalizada que se apresenta na relação presente, e que ao mesmo tempo é reatualizada e reorganizada mediante os projetos do sujeito e as situações concretas que o desafiam constantemente.

Assim, a imagem do excesso que se projeta no corpo anoréxico traduzida pelo sujeito como gordura, metaforiza significações elaboradas a partir das interações cotidianas. A gordura pode ser uma metáfora das marcas afetivas, emocionais e sócio-culturais permanentemente inscritas no corpo. De acordo com Jackson (1999), a busca por uma nova imagem e a "tendência de a imagem corporal substituir a auto-imagem quando esta é negativa ou inadequada" (p.155) revela uma tensão gerada quando há discordância ou discrepância entre a imagem real do corpo, a imagem projetada sobre o corpo e uma imagem idealizada para o corpo. Essa imagem do corpo, que forma um tipo de identidade do eu, também "serve como objeto tangível da iniciativa de autoaperfeiçoamento" (Jackson, 1999, p.156).

Ana Maria, com quase cinqüenta por cento do peso ideal para sua altura, reclamava que a preocupação da família e dos médicos era perseguição. Diane, apesar dos seus vinte e sete quilos para um metro e sessenta de altura, incomodava-se com "partes gordas" do seu corpo. Kely na sua silhueta bastante afinada sentia-se atormentada com "as pelancas entre seus dedos". E, assim, cada grama de peso que se perde torna-se uma satisfação fugaz mediante a busca incansável de uma imagem tão distante. Nesses limites do corpo, a gordura surge como uma metáfora. São as fronteiras do corpo onde a gordura metaforiza significações elaboradas nas interações cotidianas.

Qual é exatamente a natureza desse medo de comer? Parece que a dimensão simbólica do alimento, dos rituais de comensalidade e de compartilhamento alimentar, no caso da anorexia, são imagens que estão na gênese deste transtorno. Se tomarmos a alimentação como uma expressão da socialidade, um laço tão poderoso do vínculo social, não seria a anorexia nervosa uma forma de transgressão social? Pode-se tomar a anorexia, enquanto experiência do corpo que se nega a comer, como metáfora de uma resistência à convivência social - de uma forma singular de socialidade. A anorexia nervosa metaforiza a negação de um esquema corporal, no sentido que Meleau Ponty (1999) atribui ao termo. Significa a negação de um modo particular de estar-no-mundo, de uma história de vida através de uma resistência corporal ao alimento. Ou seja, a anoréxica quer negar aquilo que ela experimentou coletivamente, quer romper de certa maneira o vínculo social que a humanizou, teceu suas emoções (Maffesoli, 1998). Ao considerar a abstinência como uma resposta individual a questões sociais (Turner, 1984), a anoréxica tenta interpretar a experiência física da dieta como uma forma de sucesso pessoal diante das crises familiares, da impotência ou inabilidade em lidar com os problemas cotidianos.

\section{Notas}

1. Derivação de Giordani (2004)

\section{Referências}

American Psychiatric Association (1994). Manual diagnóstico e estatístico de transtornos mentais ( $4^{\mathrm{a}} \mathrm{ed}$.). Washington: Author.

Baudrillard, J. (1995). A sociedade de consumo. Lisboa: Edições 70.

Berger, P.L. \& Luckmann, T. (1999). A construção social da realidade. Petrópolis, RJ: Vozes.

Bidaud, E. (1998). Anorexia mental, ascese, mística. Rio de Janeiro: Cia de Freud.

Bueno, B.O.O. (2002). O método autobiográfico e os estudos com histórias de vida de professores. Educação \& Pesquisa, 28(1), 11-30.

Cordás, T.A. \& Claudino, A.M. (2002). Transtornos alimentares: fundamentos históricos. Revista Brasileira de Psiquiatria, 24 (Supl. 3) 3-6.

Dolto, F. (2001). A imagem inconsciente do corpo. São Paulo: Perspectiva.

Dunker, K.L.L., Philippi, S.T. (2003). Hábitos e comportamentos alimentares de adolescentes com sintomas de anorexia nervosa. Revista de Nutrição da PUCCAMP, 16, 51-60. 
Ferraroti, F. (1988). Sobre a autonomia do método biográfico. Em A. Nóvoa \& M. Finger (Eds.), O método (auto) biográfico e a formação (pp.17-34). Lisboa: Ministério da Saúde/Depart. de Recursos Humanos da Saúde/Centro de Formação e Aperfeiçoamento Profissional.

Giordani, R.C.F. (2004). A experiência corporal na anorexia nervosa: uma abordagem sociológica. Dissertação de Mestrado não-publicada, Programa de Pós-graduação em Sociologia, Universidade Federal do Paraná. Curitiba, PR.

Goffman, E (1988). Estigma: notas sobre a manipulação da identidade deteriorada. Rio de Janeiro: Guanabara.

Hay, P.J. (2002). Epidemiologia dos transtornos alimentares: estado atual e desenvolvimentos futuros. Revista Brasileira de Psiquiatria, 24(Supl III), 13-17.

Herscovici, C.R. \& Bay, L. Anorexia nervosa e bulimia: ameaças à autonomia. Porto Alegre: ArtMed.

Jackson, E. (1999). Alimento e transformação: imagens e simbolismo na alimentação. São Paulo: Paulus.

Joseph, I. (2000). Erving Goffman e a microssociologia. Rio de Janeiro: FGV.

Juviniano, J.M.B. (2003). Percepção da imagem corporal entre universitários da área da saúde. Monografia de Conclusão de Curso não-publicada, Universidade de São Paulo. São Paulo, SP.

Maffesoli, M. (1998).Elogio da razão sensível. Petrópolis, RJ: Vozes.

Merleau-Ponty, M. (1999). Fenomenologia da percepção. São Paulo: Martins Fontes.

Merleau-Ponty, M. (2000). O visível e o invisível. São Paulo: Perspectiva.
Robell, S. (1997). A mulher escondida: a anorexia nervosa em nossa cultura. São Paulo: Summus.

Schutz, A. (1979). Fenomenologia e relações sociais. Rio de Janeiro: Zahar.

Schilder, P.A. (1999). Imagen do corpo: as energias construtivas da psique. São Paulo: Martins Fontes.

Tavares, M.C.G.C. (2003). Imagem corporal, conceito e desenvolvimento. São Paulo: Manole.

Turner, B.S (1984). El cuerpo y la sociedad, exploraciones en teoria social. México: Fondo de Cultura Económica.

Rubia Carla Formighieri Giordani é Mestre em Sociologia pela UFPR e professora da área de Nutrição e Saúde Pública do Departamento de Nutrição/UFPR. É pesquisadora do Grupo de Pesquisa em Sociologia da Saúde e pesquisadora do Centro Colaborador em Alimentação e Nutrição do Ministério da Saúde na

Região Sul. O endereço para correspondência é Universidade Federal do Paraná, Setor de Ciências da Saúde, Campus Jardim Botânico, Departamento de Nutrição. Av. Pref. Lothário Meissner, no 3400, Jardim Botânico, CEP 80210-170, Curitiba/Paraná. rubia@ufpr.br

\section{A auto-imagem corporal na anorexia nervosa: uma abordagem sociológica}

Rubia Carla Formighieri Giordani

Recebido: 24/08/2005

$1^{\text {a }}$ revisão: 03/04/2006

Aceite final: 07/06/2006 